\title{
The Importance of Supportive Care in Breast Cancer Patients
}

\author{
Sibylle Loibl Bianca Lederer
}

German Breast Group, Neu-Isenburg, Germany

In any patient diagnosed with breast cancer the first and foremost goal is to administer the best possible care. The focus may initially lie on the surgical and medical therapy; however, to ensure supportive care delivering optimal medical therapy is equally important.

The term supportive care refers to services that help cancer patients, their caregivers, and their families to cope with the disease and its treatment throughout the patient's pathway and to help the patient maximizing treatment benefits in order to cope in the best possible way with the effects of the disease [1].

Ultimately, supportive care aims to ensure and improve the quality of life of the patient by covering different areas of supportive care, such as physical or symptom control needs, educational needs, social support, psychological support, spiritual support, and also rehabilitation support or end of life and bereavement care - a task that requires multidisciplinary cooperation and coordination [2,3].

Obviously, the supportive care needs are not the same for every breast cancer patient and differ according to the stage of the disease (early, advanced or metastatic breast cancer), the age of the patient (e.g. young women with childbearing potential or aged women), the individual social and cultural context, or simply according to individual perceptions [4]. Moreover, needs may also change during the course of the disease. Most important, however, is the fact that they have to be handled timely and appropriately.

Treatment-related toxicity and cancer pain are often acute problems in breast cancer patients, and symptom management therefore is of the highest priority. Common and severe symptoms that patients are confronted with during a (chemotherapy) treatment comprise anemia, nausea, cardiovascular toxicity, gastrointestinal symptoms, infections, and pain. National and international guidelines have been put in place in order to provide best possible supportive therapy $[5,6]$.

Educational supportive care covers any information about every aspect of breast cancer at any disease stage to enable the patient to not only understand the disease, but also the treatment options and test results.

Equally important for the patient is the social support aspect of cancer care which involves the interaction with people sharing a similar experience or dealing with the impact of the disease on personal relationships. This is also strongly associated with psychological aspects of cancer care. Psychological support is important to help patients to cope with any arising worries or fears. For patients being identified as being at risk of anxiety and depression, psychological support is all the more important, and appropriate referral mechanisms and access to affordable psychosocial experts are needed to ensure appropriate psychosocial care. A study in advanced breast cancer patients has shown that psychosocial needs were strongly associated with psychological distress and decreased quality of life and that these aspects may be improved by interventions for unmet psychological and information needs [7]. Moreover, supportive care can also comprise practical supportive care such as help when arranging travel or accommodation for treatment purposes or advice on where to get financial support or help with child care.

Generally, supportive care during and after cancer treatment is essential and should be available, affordable, and accessible for all patients and their families. However, in many cases supportive care needs are not met [4]. This is often due to the low priority of supportive care in systems with scarce resources $[8,9]$. It has been shown that failure to address supportive care during cancer treatment can bring about reduced compliance to therapy and, as a consequence, worse outcomes [8]. There is now a growing awareness of the importance of supportive care, and numerous studies have recently been looking into the assessment of supportive care needs [4].

Overall, supportive care constitutes an important part of breast cancer therapy, and further efforts are necessary to assess individual patient's needs and to provide the best possible care within a multidisciplinary setting.

\section{KARGER \\ Fax +497614520714 \\ Information@Karger.com}

www.karger.com (c) 2014 S. Karger GmbH, Freiburg

$1661-3791 / 14 / 0094-0230 \$ 39.50 / 0$

Accessible online at:

www.karger.com/brc
Prof. Dr. med. Sibylle Loibl

German Breast Group,

c/o GBG Forschungs GmbH

Martin-Behaim-Straße 12, 63263 Neu-Isenburg, Germany

sibylle.loibl@germanbreastgroup.de 


\section{References}

1 National Institute for Clinical Excellence (NICE): Guidance on Cancer Services: Improving Supportive and Palliative Care for Adults with Cancer: The Manual. London, NICE, 2004. www.nice.org.uk/ guidance/csgsp (last accessed August 12, 2014).

2 National Cancer Institute. Supportive Care. $w w w$. cancer.gov/dictionary? cdrid $=46609$ (last accessed August 6, 2014)

3 Cherny NI, Catane R, Kosmidis P; ESMO Taskforce on Supportive and Palliative Care: ESMO takes a stand on supportive and palliative care. Ann Oncol 2003;14:1335-1337.

4 Fiszer C, Dolbeault S, Sultan S, Brédart A: Prevalence, intensity, and predictors of the supportive care needs of women diagnosed with breast cancer: a systematic review. Psychooncology 2014;23:361374.

5 European Society for Medical Oncology (ESMO): ESMO Clinical Practice Guidelines: Supportive Care. www.esmo.org/Guidelines-Practice/ClinicalPractice-Guidelines/Supportive-Care (last accessed August 6, 2014)
6 Arbeitsgemeinschaft gynäkologische Onkologie e.v. (AGO): Comission Mamma. Supportive Care. www.ago-online.de/en/guidelines-mamma/march2014/ (last accessed August 6, 2014).

7 Uchida M, Akechi T, Okuyama T, Sagawa R, Nakaguchi T, Endo C, Yamashita H, Toyama T, Furukawa TA: Patients' supportive care needs and psychological distress in advanced breast cancer patients in Japan. Jpn J Clin Oncol 2011;41:530-536.

8 Cardoso F, Bese N, Distelhorst SR, Bevilacqua JL, Ginsburg O, Grunberg SM, Gralla RJ, Steyn A, Pagani O, Partridge AH, Knaul FM, Aapro MS, Andersen BL, Thompson B, Gralow JR, Anderson BO: Supportive care during treatment for breast cancer: resource allocations in low- and middle-income countries. A Breast Health Global Initiative 2013 consensus statement. Breast 2013;22:593-605.
9 Ganz PA, Yip CH, Gralow JR, Distelhorst SR, Albain KS, Andersen BL, Bevilacqua JL, de Azambuja E, El Saghir NS, Kaur R, McTiernan A, Partridge AH, Rowland JH, Singh-Carlson S, Vargo MM, Thompson B, Anderson BO: Supportive care after curative treatment for breast cancer (survivorship care): resource allocations in low- and middle-income countries. A Breast Health Global Initiative 2013 consensus statement. Breast 2013;22:606-615. 